\title{
Entre documento e ficção: fotorrelatos na Espanha da década de $1960^{1}$
}

\author{
Between document and fiction: photo-reports in Spain of the $1960 \mathrm{~s}$
}

2 Doutora em Letras Neolatinas pela Universidade Federal do Rio de Janeiro (UFRJ), professora associada IV da Faculdade de Letras da Universidade Federal de Minas Gerais (UFMG), atuando também no Programa de Pós-Graduação em Estudos Literários da FALE/UFMG. Foi coordenadora do GT/Relações 2018). Possui vários artigos publicados memória da Guerra Civil Espanhola na literatura e nas artes e recentemente coorganizou os livros Imagem e Memória (2012), Em torno da imagem e da memoria (2016), Modos de Arquivo: literatura, critica, cultura (2018) e Literatura, outras Artes e Violência nas Américas (2019). Tem experiência na area de Letras, com ênfase em Literatura Espanhola, com a história e a memória cultural, assim como com outras artes e mídias. Atua principalmente no âmbito da teoria literária, literatura espanhola e fotografia. Em 2018, desenvolveu pesquisa de pós-doutorado no Programa de Pós-Graduação em Literatura, Cultura e Contemporaneidade da PUC-Rio, com o projeto dos anos 60"

(1)

E-mail: elisa.amorim@terra.com.br

Recebido em: 4/5/2019

Aprovado em: 5/7/2019.

Carlos, 6627, Pampulha, Belo Horizonte, MG, CEP: 31270-901.
Elisa Maria Amorim Vieira ${ }^{2}$ Universidade Federal de Minas Gerais, Programa de Pós-Graduação em Letras: Estudos Literários, Belo Horizonte, MG, Brasil.

\section{RESUMO}

O principal objetivo deste trabalho é analisar o ressurgimento do gênero costumbrista na Espanha da década de 1960, quando relatos de cenas do cotidiano e retratos de tipos urbanos passaram a ser acompanhados de fotografias-documento. Nesse período, a relação entre texto literário e fotografia foi amplamente cultivada através da publicação de uma série de fotolivros, tanto na Espanha quanto na América Latina. 0 corpus principal desta pesquisa é o fotolivro Nuevas escenas matritenses, que reúne fotografias de Enrique Palazuelo e textos de Camilo José Cela, no qual a aproximação entre palavra e imagem ora potencializa o processo de fabulação, ora gera tensão entre os dois meios. Para a realização dessa análise, recorreu-se às reflexões de Joan Fontcuberta e André Rouillé sobre os limites e o poder transformador do realismo fotográfico, assim como às observações de Christoph Rodiek sobre a obra de Camilo José Cela e às de Karl Erik Schøllhammer sobre a relação entre palavra e imagem.

Palavras-chave: Fotorrelatos. Costumbrismo. Cidade. Espanha. Década de 1960.

\section{ABSTRACT}

The main objective of this work is to analyze the resurgence of the costumbrista genre in Spain during the 1960s, when reports of daily scenes and portraits of urban characters started to be accompanied by documentart photographs. In this period, the relationship between the literary text and the photography was widely developed through the publication of a series of booklets, both in Spain and in Latin America. The main corpus of this research is the new book Nuevas escenas matritenses, which brings together photographs by Enrique Palazuelo and texts by Camilo José Cela. In this work, the approximation between word and image either enhaces the storytelling process or generates tension between the two media. In order to carry out this analysis, we resorted to the reflections of Joan Fontcuberta and André Rouillé on the limits and transformative power of photographic realism, as well as to the observations of Christoph Rodiek on the work of Camilo José Cela and Karl Erik Schøllhammer about the relations between word and image. Keywords: Photo-reports. Costumbrismo. City. Spain. 1960s. 
"Pero el testigo que ve y dice verdad, ¿no será justamente el fantasma entre dos zonas, el vigía entre sueño y despertar, allí donde las fronteras de la costumbre ceden al furtivo encuentro de los contrarios, a la reconciliación de lo absurdo y lo evidente, al paseo de este hombre que a la altura de Talcahuano y Corrientes mira las luces de un café que no conoció nunca, se acerca a una mujer que no le tenderá la mano?"3

(Julio Cortázar)

$A^{\text {s }}$

longo da década de 1960, tanto na Espanha quanto em diversos países latino-americanos, foi possível assistir a uma verdadeira profusão de fotolivros, sendo que a maior parte dessas publicações estava dedicada ao espaço urbano, principalmente às grandes metrópoles. Muitas dessas obras combinavam fotografias de artistas renomados ou que começavam a conquistar espaço no mundo da arte e da fotografia documental, com textos de escritores já consagrados. Esse desejo de representação dos espaços urbanos, em um momento de euforia desenvolvimentista, buscava unir ideias de cidade e ficções com a visibilidade de um território particularmente instável. Na base desse movimento, percebe-se tanto a necessidade de construir utopias quanto a de reter determinados aspectos da vida cotidiana e da memória da cidade.

Um exemplo deste último traço, relacionado ao desejo de construir um acervo de imagens e memórias do espaço urbano, é o paradigmático Buenos Aires, Buenos Aires (1968), livro que conjuga fotografias de Alicia D'Amico e Sara Facio com textos de Julio Cortázar. Para isso, as imagens realizadas pelas duas jovens fotógrafas argentinas não se detêm nos monumentos arquitetônicos da cidade, assim como evitam temas pitorescos. Como observa o próprio Cortázar, aquelas imagens, realizadas a partir de percepções afetivas da metrópole, nascem "dos gestos interiores de uma sensibilidade que coincide com a razão estética para que cada abertura sobre a cidade tenha algo do lenço da Verônica,

"Mas o testemunho que vê diz a verdade, não será justamente o fantasmas entre duas zonas, o vigia entre sonho e despertar, ali onde as fronteiras do costume cedem ao furtivo encontro dos contrários, à reconciliação do absurdo e do evidente, ao passeio deste homem que à altura de Talcahuano e Corrientes lha as luzes de um café que nunca conheceu e se aproxima a uma mulher que não lhe estenderá a mão?" (Tradução nossa).

Letrônica | Porto Alegre, v. 12, n. 3, jul-set 2019: de linho enxugando um rosto molhado pela vida"4 (1968, p. 22-23, tradução nossa). ${ }^{5}$ As fotógrafas, que evitam as "cenografias mortas" da fotografia moderna (FERNÁNDEZ, 2011, p. 90), permitem o protagonismo de pedestres, frequentadores de cafés, vizinhas reunidas na calçada, crianças em procissão, trabalhadores, dentre outros, enquanto o texto de Cortázar as perpassa para alcançar uma experiência do olhar que as mescla com as pós-imagens ${ }^{6}$ de sua memória e as originadas como reflexo de outras óticas. Ao comentar o que escreve Cortázar, desde seu exílio em Paris, instigado por aquelas fotografias de Buenos Aires, Saúl Sosnowski (2014, p. 98, tradução nossa) comenta: "A cidade para a qual se volta tem um tinte nostálgico, um cariz mais meloso ou mais acre que é fiel aos ressaibos da recordação ou do desejo" ${ }^{7.8}$

Por outro lado, dois fotolivros que se ocupam da nascente capital do Brasil expressam mais claramente a necessidade de construir utopias. São eles: Doorway to Brasilia (1959), livro de Aloísio Magalhães e Eugene Feldman, e Brasília vive! (1960), de Peter Scheier e John Konx. O primeiro, considerado como livro de artista, foi publicado na Filadélfia um ano antes da inauguração da nova capital e se destaca por desenvolver uma sofisticada montagem das imagens e de textos de Juscelino Kubitschek, Oscar Niemeyer, Lúcio Costa, além do prefácio do escritor John dos Passos. As imagens de formas indefinidas e de detalhes da natureza do cerrado brasileiro vão se aproximando as dos andaimes e as dos edifícios em construção, enquanto alguns textos, como o de JK e o de John dos Passos, destacam o silêncio e o ruído das máquinas. Por sua vez, Brasília vive! tem um tom mais laudatório, evidenciado pelas imagens da monumentalidade das obras criadas por Oscar Niemeyer e do traçado urbano

Do original: los gestos interiores de una sensibilidad coincidiendo con la razón estética para que cada apertura sobre la ciudad tenga algo de velo de la Verónica, de lino enjugando una cara mojada por la vida. Todas as traduções deste texto são de autoria própria.

Refiro-me aqui à pós-imagem retiniana. Jonathan Crary estuda esse fenômeno a partir da Doutrina das cores, de Goethe, no capítulo sobre as cores fisiológicas. Como explica Crary, o fenômeno da pós-imagem pode ser entendido como uma percepção sensorial separada de qualquer vínculo com um referente externo. A pós-imagem seria, então, "a presença da sensação na ausência de um estímulo" (CRARY, 2012, p. 99). No caso de Buenos Aires, Buenos Aires, Julio Cortázar, desde o exílio parisiense, aproxima as imagens realizadas pelas duas fotógrafas às pós-imagens da cidade que ele guarda em sua memória.

SOSNOWSKI, Saúl. «El que vuelve» está en casa: Buenos Aires en Cortázar". Disponível em:http://www. casadelasamericas.org/publicaciones/revistacasa/278/notas.pdf. Acesso em: 14 fev. 2019.

8 Do original: La ciudad a la que se vuelve tiene un tinte nostálgico, un cariz más meloso o más acre que es fiel a los resabios del recuerdo o del deseo. 
de Lucio Costa. 0 livro, que utiliza poucos textos, traz ainda algumas cenas do cotidiano dos trabalhadores da nova cidade, quase sempre em espaços públicos, tais como feiras, restaurantes, supermercados e praças. Também é possível observar nesse fotolivro as contraposições entre fotografias de Juscelino Kubitschek e as dos candangos, em que fica evidente o enaltecimento da figura do presidente e a tipificação do trabalhador. 0 que salta aos olhos nessas duas publicações é a incomensurável carga simbólica da nova capital que, construída em meio ao cerrado, com uma arquitetura e um traçado urbano modernos, seria o próprio símbolo utópico do desenvolvimento do país.

Para Beatriz Sarlo (2010, p. 146), a cidade escrita pode ser tanto uma cidade realmente existente, "um composto de cidades vistas, vividas e recordadas; ou uma cidade de completa invenção: uma distopia, como as cidades da ficção científica, das ficções políticas ou da literatura fantástica". Nos exemplos anteriores, podemos comprovar que a cidade escrita e fotografada tem como ponto de fuga uma cidade ideal, "que está no passado (a fuga é nostálgica ou melancólica) ou no futuro (a fuga é utópica e reformadora)"9 (SARLO, 2010, p. 147, tradução nossa). Sarlo ressalta ainda a força preceptiva da cidade escrita: escreve-se o que se recorda e o recordado não coincide com a cidade real; assim, "a literatura se refere às consequências da desaparição da velha cidade ou à emergência da cidade nova"10 (2010, p. 147, tradução nossa). Os textos de Cortázar e as fotos de Facio e D’Amico, em Buenos Aires, Buenos Aires, e, por outro lado, o prólogo de John do Passos e o trabalho gráfico Magalhães e Feldman, em Doorway to Brasilia, confirmam esse preceito.

O fenômeno dos fotolivros da década de sessenta, no entanto, não se detém somente na configuração da cidade utópica ou melancólica, mas também na exploração das possibilidades criativas dadas pela aproximação entre escrita literária e imagem fotográfica. Ao comentar, desde uma perspectiva mais ampla, a complementaridade entre os dois meios, Karl Erik Schøllhammer (2016, p. 8) observa que a imagem é muitas vezes empregada para "ilustrar" a palavra, iluminando aquilo que se considera obscuro, ou, então, é a palavra que determina o sentido da imagem, em contraposição ao "poder sedutor da

Do original: [...] que está en el pasado (la fuga es nostálgica ou melancólica) ou no futuro (a fuga é utópica ou reformadora).

Do original: "la literatura se refiere a las consecuencias de la desaparición de la vieja ciudad o a la emergencia de la ciudad nueva". representação imediata". Para além da incompatibilidade entre a potência imaginativa da palavra e a proliferação de imagens pré-fabricadas e banalizadas da mídia, Schøllhammer afirma que: "As imagens visíveis são fontes de inspiração para a produção literária, mas na literatura as imagens visíveis se cruzam com as não visíveis e estabelecem com elas uma relação de mútua inspiração" (2016, p. 9). Quando Cortázar escreve sobre Buenos Aires, a partir das fotografias de Sara Facio e Alicia D’Amico, certamente o faz em diálogo com as imagens de sua memória e as de um amplo acervo de referências literárias que povoam seu imaginário.

Na Espanha dos anos sessenta, uma série de publicações, em especial a coleção Palabra e Imagem, irá impulsionar a aproximação entre os dois meios, possibilitando tanto o fortalecimento da fotografia documental e neorrealista, que se contrapunha à estética vigente no período franquista, quanto o ressurgimento do relato costumbrista que já ocupara um papel relevante no cenário cultural espanhol do século XIX. Os fotolivros serão, portanto, um veículo fundamental para a consolidação de alguns nomes que terão um papel essencial na história da fotografia espanhola do século XX: Joan Colom, Xavier Miserach, Ramón Masats, Jaime Buesa, Catalá-Roca, Oriol Maspons, Francisco Ontañón, entre outros. Em contrapartida, no campo literário, foram muitos os escritores que aceitaram a experiência de unir palavra e imagem - Ana María Matute, Miguel Delibes, Rafael Alberti, Mario Vargas Llosa, Pablo Neruda etc. -, porém, neste trabalho, se dará um destaque especial a Camilo José Cela, ${ }^{11}$ seja pela profusão de fotorrelatos que escreveu, seja pelo caráter inovador e também questionável, do ponto de vista ético, dessa produção.

11 Camilo José Cela (1916-2002) foi um dos grandes escritores espanhóis do século XX. Em 1989, recebeu o Prêmio Nobel de Literatura e, em 1995, o Prêmio Cervantes. Cela é autor de diversos romances - entre eles, La familia de Pascual Duarte (1942), La colmena (1951) e Madera de Boj (1999) -, além de contos, fábulas, poesias, peças de teatro, artigos, narrativas de viagens e obras de lexicografia. 


\section{Fotolivros na Espanha da década de 1960: a coleção Palabra e Imagen}

Na Espanha do início da década de 1960, a incipiente editora Lumen, sob a direção dos jovens Óscar e Esther Tusquets, leva a cabo um ambicioso projeto editorial, a coleção Palabra e Imagen, publicada de 1961 a 1985. A série de fotolivros teria começado quando o fotógrafo Jaime Buesa oferece aos dois irmãos editores o Libro de juegos para los niños de los otros (1961), um trabalho realizado em parceria com a escritora Ana María Matute. 0 projeto fascinou tanto a fotógrafos, que buscavam a oportunidade de ter sua obra publicada em livro, quanto a escritores já consagrados, que poderiam publicar narrativas breves em edições esteticamente muito elaboradas. Por sua vez, para os editores, a coleção significava a oportunidade de participar mais ativamente do planejamento das várias etapas da publicação, desde a escolha da capa e do título até a do seu lançamento. Segundo Esther Tusquets (2010, p. 8), a intenção era a de que as fotografias tivessem a mesma importância que os textos ${ }^{12}$. Nesse sentido, o ideal seria que fotógrafos, escritores e editores trabalhassem juntos. Dos muitos títulos da coleção, Tusquets se refere a dois em que essa colaboração de fato ocorreu: La caza de la perdiz roja (1963), com textos de Miguel Delibes e fotos de Oriol Maspons, e Una casa en la arena (1966), de Pablo Neruda e Sergio Larraín ${ }^{13}$.

Porém, de todos os fotolivros da coleção Palabra e Imagem, o que teve maior êxito editorial foi, segundo a própria Esther Tusquets, o afamado Izas, rabizas y colipoterras (1964), com textos de Camilo José Cela e fotografias de Joan Colom. São muitas as histórias e especulações que cercam essa publicação, mas se nem todas são reais, a maior parte delas nos oferece elementos para entender o contexto em que se produziram. A própria participação de uma

É bastante elucidativa a citação que Esther Tusquets faz de Carlos Barral, da editora Seix Barral, sobre colaboração entre Vargas Llosa e Xavier Miserachs, na qual ele afirma que o escritor peruano e o fotógrafo catalão jamais teriam aceitado a colaboração se não estivessem seguros de sua total independência. Nem Miserachs aceitaria ilustrar o texto servilmente, nem Vargas Llosa admitiria que elementos de sua imaginação coincidissem com as imagens do fotógrafo (TUSQUETS, 2010, p. 12)

3 No Prólogo da nova edição de Los Cachorros, texto de Mario Vargas Llosa e fotografias de Xavier Miserachs, publicada pela editora La Fábrica, em 2010, Esther Tusquets se equivoca ao atribuir as fotos de Una casa en la arena ao italiano Paolo Gasparini, quando na verdade são do fotógrafo chileno Sergio Larrain a quem Neruda teria indicado o que deveria ser fotografado. Gasparini foi o fotógrafo de La ciuded de las columnas, cujo texto é de Alejo Carpentier. personalidade tão ambígua como a de Cela, que encarnava o grande escritor que conseguia manter relações amistosas com a ditadura franquista, ao mesmo tempo em que promovia os escritores exilados pelo regime através dos Papeles de Son Armadans ${ }^{14}$, já seria o suficiente para semear uma incerta aura em torno de Izas, rabizas y colipoterras. 0 contraste com a figura discreta do fotógrafo amador e contabilista de profissão, Joan Colom, talvez tenha contribuído a fomentar ainda mais as lendas em torno da obra. 0 fato é que a editora Lumen, em pleno ambiente conservador e retrógrado do franquismo ${ }^{15}$, decide publicar um livro cujo tema são as prostitutas do Barrio Chino barcelonês ${ }^{16}$. Como bem apontou Joan Fontcuberta (1998, p. 186), o resultado dessa parceria corroborava perfeitamente a proposta da coleção Palabra e Imagem, segundo a qual os dois discursos eram vistos como paralelos, sem que a fotografia tivesse uma relação de submissão com respeito ao texto. No caso em questão, foram as imagens de Colom que desencadearam o texto de Cela e não o contrário.

Desde uma perspectiva contemporânea sobre o direito à imagem e, mais do que isso, um olhar sensível aos debates em torno da condição da mulher ao longo da história, Izas, rabizas y colipoterras encerra uma série de problemas de caráter ético. Joan Colom, que se tornara uma referência para a renovação da fotografia na Espanha, havia realizado a série de imagens das prostitutas do Barrio Chino sem pedir consentimento as suas modelos. 0 discreto funcionário,

Revista literária publicada por Cela, em Palma de Mallorca, de 1956 a 1979. Sobre esse tema, ver a tes "Bastidores de Papeles de Son Armadans: as correspondências", de Solange Chagas de Nascimento Munhoz da Universidade de São Paulo.

O general Francisco Franco tomou o poder na Espanha em 1939, após o término de uma sangrenta Guerra Civil (1936-1939) que matou em torno de 500 mil pessoas. Segundo a historiadora Paloma Aguila Fernández (2008, p. 95-96), ao longo de trinta e seis anos, o país foi governado por uma elite de composição heterogênea sob a liderança permanente do ditador. 0 poder dessa elite política se sustentava em instituições de tipo totalitário em suas origens, mas que aos poucos passou a adotar formas autoritárias. Durante todo esse período, o regime não só ostentou sua vitória, como discriminou e perseguiu durament os vencidos da Guerra Civil. Nas últimas duas décadas, tem havido um intenso trabalho de recuperação da memória histórica na Espanha, especialmente com a criação, em 2000, da Asociación para la Recuperación de la Memoria Histórica (ARMH). A literatura, o teatro, a fotografia e o cinema têm desempenhado um pape extremamente relevante no sentido de provocar a reflexão em torno da memória dos vencidos.

O Barrio Chino, em espanhol, Barri Xino, em catalão, ou Raval, sempre foi um território dissidente na geografia barcelonesa. Antes e durante a Guerra Civil Espanhola (1936-1939), foi reduto de operários pobres e, principalmente, de anarquistas. Em 1933, período republicano, os desvalidos do bairro foram intensamente retratados pela fotógrafa austríaca, Margaret Michaelis. Durante o regime franquista, tornou-se território de prostituiç̃ã e da vida marginal. Atuarmete apesar dita tentativas de gentrificacão e do boom do turismo, o bairro ainda é um tradicional albergue de imigrantes ilegais. 
como observa Fontcuberta, "se transformava em um sigiloso espião das intimidades secretas" (1998, p. 186, tradução nossa) ${ }^{17}$, um voyeur que escondia sua Leica para captar de forma clandestina as cenas cotidianas de um território ao qual ele não pertencia. Imbuído de seu papel de testemunho imparcial, Colom não buscava interagir com as suas presas. Tamanha indiscrição fez com que uma das mulheres fotografadas, Eloísa Sánchez, denunciasse Colom, Cela e a editora por ter exposto sua imagem sem seu consentimento. Esse conhecido e comentado episódio representou uma ruptura traumática na carreira do fotógrafo, levando-o a abandonar a fotografia por vinte anos. Suas imagens, no entanto, constituem um acervo fundamental tanto para a história da fotografia na Espanha quanto para a memória visual da Barcelona dos anos 1950.

Por sua vez, os relatos de Camilo José Cela apresentam de maneira sarcástica e cruel, não isenta de engenhosidade, 52 sinônimos da palavra prostituta em espanhol. A obra se divide em cinco capítulos, organizados de acordo com a idade ou tipo das prostitutas: izas, rabizas, colipoterras, hurgamanderas e putarazanas. Na primeira fotografia do livro, vê-se entreaberta a grande porta de um bar, na qual está escrito "Bocadillos variados", e por onde se assoma o rosto de uma mulher loira que olha para o exterior. Nada nessa imagem indica que se trata do retrato de uma trabalhadora sexual, a não ser o fato de estar publicada juntamente com uma série de fotografias em que os gestos, vestimentas e situações deixam mais clara a referência ao universo da prostituição. Essa primeira foto joga de maneira categórica com os dois fora de campo da imagem, tanto o que indica aquilo estaria no interior do bar quanto o que seria objeto do olhar da mulher. Enquanto primeira fotografia do livro, o movimento dessa figura feminina, que remete ao mito de Penélope, é o daquela que espera, sejam amantes, clientes ou leitores. Para corroborar essa possível leitura da imagem, temos o texto de Cela que a acompanha, intitulado "Pregão", e que se apresenta como um chamado aos passantes:

- Passem, senhores, passem e vão passando! Aqui poderão ver a autêntica Vênus Callipigia, com a vergonha a ponto, com uma teta à mostra e a bunda de fora! Entre, cavalheiro, a gozar dos antigos prazeres do amor! Espetáculo permitido pela polícia! A Ninfa da primavera, de Cranach, pelada e com dois

Do original: es transformava en un sigi冋lós espia de les intimitats secretes. perdizes picando a verde e fresca erva! A Diana adolescente, de Boucher, está com as perdizes já mortas e a ponto de assar! Ouça, cidadão, que quando estiver morto será tarde demais! [...] Só para homens! Vênus e Cupido, pelo divertidíssimo Bronzino! La Maja desnuda, de Goya, e Mademoiselle Naná de anáguas ou o resgate da ingenuidade, pelo francês Manet! Aqui se faz à francesa e o que mais se quiser! Há sanduíches variados e numerosas senhoritas. Passem, senhores, passem, e vão passando" (1984, p. 7, tradução nossa) ${ }^{18}$

A partir desse anúncio, já se estabelece um pacto de leitura em que o leitor intui o que encontrará por diante: uma mostra de mulheres expostas ao olhar indiscreto do fotógrafo e às palavras sarcásticas e pouco lisonjeiras do escritor. No entanto, como observa Christoph Rodiek (2008, p. 110), o que se verá é que a sobriedade do enfoque neorrealista de Joan Colom é incompatível com os jogos de estilo de Cela: "Se as fotos de Colom estão arraigadas dentro de uma orientação temática e estética determinada, Cela cultiva uma leitura criativa que é, ao mesmo tempo, antitemática, irônica e subversiva"19 (RODIEK, 2008, p. 111, tradução nossa). 0 escritor se vale da fotografia-documento, que se propõe a ser testemunho do real, para construir narrativas pouco confiáveis e um universo ficcional marcado por uma retórica abusiva, carregada de animalizações, anáforas e o que Rodiek chama de "intertextualidade lúdica". O fotorrelato intitulado "Zorrastrón cumplido", que acompanha a fotografia de uma mulher corpulenta, vista em primeiro plano e caminhando diante de um bar, é um exemplo contundente dessa retórica:

A mulher, o melão e o queijo, ao peso. Toma do frasco, Carrasco, que sa um miúra pela porta grande! As mouras murcianas, passando de certa tonelagem, costumam ser um bocado saboroso para judeus manchegos e demais fauna a quem a lei veda provar o toucinho fora do catre.

18 "Do original: - ¡Pasen, señores, pasen y vayan pasando! ¡Aquí podrán ver la auténtica Venus Callipigia con la vergüenza a punto, con una teta al aire y el culo fuera! iEntre usted, caballero, a gozar de los antiguos placeres del amor! ¡Espectáculo permitido por la policía! ¡La Ninfa de la primavera, de Cranach, en cueros vivos y con dos perdices picando la verde y fresca yerba!! La Diana adolescente, de Boucher, ésta con las perdices ya cadáveres y a punto de asador! ¡Oído, ciudadano, que cuando llegue usted a cadáver será tarde! [...] ¡Sólo para hombres! ¡Venus y Cupido, por el cachondísimo Bronzino! ¡La Maja desnuda, de Goya, Y Mademoiselle Naná en enagua o el rescate de la ingenuidad, por el francés Manet! iAquí se hace el francés y lo que se tercie! ¡Hay bocadillos variados y numerosas señoritas! ¡Pasen, señores, pasen y vayan pasando ${ }_{19}$ Do original: $\mathrm{Si}$ las fotos de Colom están arraigadas dentro de una orientación temática y enfática determinada, Cela cultiva una lectura creadora que es, a la vez, antitemática, irónica y subversiva. 
$[\ldots]$

Maimónides, judeu aristotélico cordobés, conta em seu Guía dos perplexos e desencaminhados as façanhas de Ghenziana-Sara Turquí, também conhecida por Sarita Congro, marafona completa, natural de Baena [... $]^{20}$ (CELA, 1984, p. 56-59, tradução nossa).

As referências sociais e históricas da fotografia, percebidas pelo tipo de roupa que usa a mulher e pelos demais elementos da imagem (um marinheiro de costas, uma dona de casa e um homem mais velho conversando diante do bar), ficam totalmente anuladas pelo relato burlesco de Camilo José Cela, que relaciona a mulher da foto a um touro (miúra) e as murcianas à comida. Na edição de 1971 de Izas, rabizas y colipoterras, realizada pela mesma editora, mas já sem as fotografias de Joan Colom, Cela escreve uma espécie de prólogo intitulado "Breve nota resignada", no qual lamenta que a primeira recepção do livro tenha sido "acidentada e tumultuada" e, usando uma retórica cervantina, declara: "as pessoas não leem, ou leem mal e depressa, e têm pouca memória, precário entendimento e má vontade, e assim não há maneira de salvar a alma" ${ }^{{ }^{21}}$ (1971, p. 9, tradução nossa). Naquele momento, o escritor galego tinha plena consciência de que seu texto, sem as fotografias de Colom, para as quais fora escrito, era capenga: "Minhas izas, minhas rabizas, minhas colipoterras, minhas hurgamanderas $\mathrm{e}$ minhas putarazanas - que os deuses se apiedem de suas dilaceradas carnes! iniciam hoje essa nova andadura que bem sei coxa, por sua e minha [causa], mas que não quisera feridora para os demais"22 (CELA, 1971, p. 10, tradução nossa).

A relação de Camilo José Cela com a fotografia já era conhecida desde a primeira edição de Viaje a la Alcarria, de 1948, que foi publicada com imagens realizadas pelo fotógrafo austríaco Karl Wlasak. Os relatos, distribuídos em 11 capítulos, narram

20 Do original: La mujer, el melón y el queso, al peso. ¡Toma del frasco, Carrasco, que sale un miura por la puerta grande! Las moras murcianas, en pasando de cierto tonelaje, suelen ser bocado gustoso para judíos manchegos y demás fauna a quien la ley veda catar el tocino fuera del catre. [...]

Maimonides, judío aristotélico cordobés, cuenta en su Guía de perplejos y descarriados las hazañas de Ghenziana-Sara Turquí, también conocida por Sarita la Congrio, zorratrón cumplido natural de Baena [...].

1 Do original: la gente no lee, o lee mal y deprisa, y tiene poca memoria, precario entendimiento y mala voluntad, y así no hay modo de salvar el alma.

22 Do original: Mis izas, mis rabizas, mis colipoterras, mis hurgamanderas y mis putarazanas -ique los dioses se apiaden de sus laceradas carnesl- inician hoy esta nueva andadura que bien sé cojitranca por suya y mía, pero que no quisiera heridora para los demás. a caminhada de algumas semanas empreendida pelo próprio Cela pela parte sul da meseta espanhola, em que o escritor destacava a beleza dos lugares por onde passara, a variedade da produção rural, a generosidade do povo e, em palavras suas, o maravilhoso castelhano falado na região. Relatos em que se pode perceber a empatia do escritor com o que descreve e narra, muito distinto do registro zombeteiro, depreciativo e misógino utilizado em Izas, rabizas y colipoterras. A relação com a imagem em ambos os livros também é bastante distinta. Enquanto em Viaje a la Alcarria as fotografias ilustram o texto, no fotolivro de 1964 são elas que dão origem aos breves relatos biográficos criados por Cela.

No entanto, as verdadeiras predecessoras de Toreo de salón (1963), ${ }^{23}$ de Izas, rabizas y colipoterras (1964) e das Escenas matritenses ou Fotografías al minuto (1965-66) são as breves narrativas reunidas na seção intitulada "Doce fotografias al minuto" do livro El gallego y su cuadrilla, de 1955. Apesar do título, os relatos não se fazem acompanhar de imagens fotográficas, uma vez que elas são apenas sugeridas ou comentadas pelo protagonista. A narrativa de abertura, "Sansón García, fotógrafo ambulante”, apresenta aquele que será o personagem central de todas as outras: um fotógrafo caolho, falador e itinerante. 0 narrador dos relatos é sempre o mesmo, alguém que vê as fotografias, escuta as histórias por elas suscitadas e, vez por outra, interpela ou consola o fotógrafo falante em seus acessos de melancolia. Algumas vezes, porém, quando o fotógrafo é totalmente tomado pela verborragia, ele próprio assume o papel de narrador, como no relato "Sansón García tiene ganas de hablar". As imagens, apenas referidas ou, quando muito, descritas, são o elemento desencadeador das recordações do fotógrafo: "Deve estar por aqui uma foto de Wenceslao. Sim, aqui está ela. Este sujeito é o Wenceslao. Que pinta, hein! o Wenceslao era um artista muito autodidata e muito corpulento, que andava com uns trejeitos muito marciais [...]" ${ }^{24}$ (CELA, 1981, p. 240, tradução nossa).

Se considerarmos os procedimentos seguidos em "Doce fotografias al minuto" e sua semelhança com os que foram adotados posteriormente em Izas, rabizas y colipoterras, poderíamos correr o risco de acreditar que as fotografias

3 Obra também publicada na coleção Palabra e Imagem, contou com fotografias de Oriol Maspons e Julio Ubiña. 0 cenário principal das fotografias em Toreo de Salón foram as academias de tauromaquia situada na periferia de Barcelona. 0 ensaio fotográfico de Maspons e Ubiña já havia sido realizado quando Cela foi convidado a escrever os fotorrelatos.

24 Do original: Por aquí debe de andar una foto del Wenceslao. Sí, mírela aquí. Este tío es el Wenceslao. ¡Qué facha, eh! El Wenceslao era un artista muy autodidacta y muy corpulento, que andaba con unos contorneos muy marciales $[\ldots]$ 
de Joan Colom eram desnecessárias para que Cela escrevesse seus relatos. Christoph Rodiek (2008, p. 107) observa, porém, que o que interessava a Cela era o efeito de ficção ressaltado a partir do choque de campos de referência empíricos e ficcionais, o que teria sido intensificado nos fotorrelatos. As fotografias de Colom lhe davam a possibilidade de jogar com os "registros da realidade" para criar biografias falsas e fabular aquilo que seria tomado como verdadeiro. Talvez seja possível perceber uma certa afinidade entre esse jogo picaresco de Cela, realizado a partir das fotos de Colom, com as séries fotográficas de Joan Fontcuberta, ${ }^{25}$ que desestabilizam o caráter indiciário e referencial da fotografia ao inserir a ficção no próprio processo de elaboração de suas imagens. Embora os procedimentos sejam totalmente distintos, tanto em um caso quanto no outro a ficção surge como o elemento desestabilizador da ilusão de realidade proporcionada pela imagem fotográfica.

Como afirma o próprio Fontcuberta (2010, p. 104), a modernidade fotográfica situava no documento a verdadeira essência do meio e se a imagem técnica se implantou em todos os recantos da vida foi justamente por sua condição de testemunho do real. Sem esquecer toda uma corrente que buscava aproximar a fotografia da pintura, produzindo efeitos subjetivos nas imagens fotográficas, o objetivismo do meio acaba predominando. Apesar de ter-se firmado como um "discurso" a serviço da verdade, o realismo fotográfico, diz Fontcuberta (2010, p. 10), "escondia em um beijo sua traição". Todas as possíveis manipulações que podem ser produzidas em uma imagem fotográfica - e a história da fotografia é pródiga nesse assunto - acabam tornando-se evidentes com o advento da fotografia digital, que permite que qualquer pessoa as opere desde a tela de um celular. As possibilidades de fabulação seriam, portanto, inerentes à própria imagem fotográfica. Os fotorrelatos podem intensificar essa potencialidade fabuladora ou, ao contrário, podem gerar uma tensão entre relato ficcional e fotografia-documento.

André Rouillé (2009, p. 103), por sua vez, chama atenção para outro aspecto fundamental: o de que a fotografia-documento transformou completamente os modos de visão e de representação tradicionais. A oposição que a fotografia estabelece com a pintura, segundo o teórico francês, não é somente a que se dá

25 Nesse sentido, são emblemáticos os seguintes trabalhos de Fontcuberta: Fauna (1987), Constelaciones (1993), Sputnik (1997), Sirenas (2000), Milagros \& Co (2002), La isla de los vascos (2003) y Deconstructing Osama (2007). pela substituição da mão do artista pela máquina, "mas pelo fato de produzir, do real, imagens fragmentárias, atomizadas, fracionadas, não hierarquizadas" (ROUILLÉ, 2009, p. 103). Dois mundos entrariam, então, em confronto: um que acredita poder unificar os fragmentos, enquanto o outro acumula fragmentos não totalizáveis. "É um fenômeno mais geral da modernidade, que atinge tanto a produção, com o desenvolvimento da indústria, quanto a literatura e a imprensa" (ROUILLÉ, 2009, p. 104). Nesse sentido, a informação, que passaria a competir com a narrativa, justapõe notícias que não têm correlação entre si. 0 jornal, a partir da segunda metade do século XIX, fragmenta as narrativas e torna mais complexa a perspectiva. A publicação de romances em fascículos está, sem dúvida, ligada a esse fenômeno. Por sua vez, o surgimento, no início do século XIX, de um novo gênero literário - o relato costumbrista - também está diretamente relacionado com a grande imprensa e com a observação da vida cada vez mais atomizada das grandes cidades. Já o ressurgimento do costumbrismo na década de 1960 , quando os relatos de cenas do cotidiano e retratos de tipos urbanos passam a ser acompanhados de fotografias-documento, potencializa novos olhares sobre o espaço urbano e a fabulação advinda da aproximação entre os dois meios.

\section{Vivir en Madrid e Nuevas escenas matritenses: a reinvenção do costumbrismo}

Assim como as capitais mencionadas no início deste artigo, também Madri foi objeto privilegiado de fotolivros na década de 1960. Um exemplo significativo desse tipo de produção editorial é o clássico Vivir en Madrid (1967), da editora Kairós, com textos do jornalista Luis Carandell e fotografias de Francisco Ontañón. Essa publicação retoma de forma deliberada a tradição do costumbrismo do século XIX, que tantas vezes se deteve nos hábitos cotidianos e nos tipos que compunham a capital da Espanha. A obra se divide em duas partes, sendo que a primeira, intitulada "Velázquez", está composta de onze crônicas acompanhadas de suas respectivas fotografias, enquanto a segunda, "Goya", apresenta treze crônicas e um dicionário madrilenho-castelhano, além das fotografias que as seguem. 0 texto de abertura, "A manera de Prólogo", tem como epígrafe um trecho de Historia de la vida del Buscón, de Francisco de Quevedo, no qual 
se lê: "O primeiro que deves saber é que na corte há sempre o mais tonto e o mais sábio, mais rico e mais pobre, e os extremos de todas as coisas..." ${ }^{26}$ (CARANDELL, 1971, p. 9, tradução nossa). 0 cenário desse primeiro texto, que irá confirmar a epígrafe de Quevedo, é a chocolataria do bairro Lavapiés, local propício à apresentação dos costumes noturnos e matinais dos madrilenhos. 0 texto também faz indicações geográficas precisas e dá informações sobre as vestimentas e os penteados usados pelos frequentadores do estabelecimento. Seguindo à risca a castiça tradição costumbrista, o pequeno, mas significativo espaço comercial, tem a capacidade de condensar toda a comunidade da capital espanhola: "Desses dois milhões e meio de habitantes que não sabemos quem são, como pensam nem como vivem, há uma representação completa na chocolataria de Lavapiés, às cinco da manhã" ${ }^{27}$ (CARANDELL, 1971, p. 12, tradução nossa).

A primeira parte de Vivir en Madrid, "Velázquez", está geograficamente delimitada pelos bairros e ruas mais ricos e monumentais da cidade. A diferenciação que o autor traça entre os vários espaços da capital, tendo os dois pintores, Velázquez e Goya, como referência, fica evidente no texto de abertura da primeira parte:

Madri, ao amanhecer, é de Velázquez. De dia, é de Goya. As casas dos ricos, os jardins, os passeios, os edifícios públicos e os bares elegantes são de Velázquez. O Rastro, os mercados, a Casa de Campo, os domingos, a Puerta del Sol, o Gran San Blas, o metrô e os botequins são de Goya ${ }^{28}$ (CARANDELL, 1971, p. 19, tradução nossa).

Como se pode notar, a própria concepção da obra está definida pela visibilidade. As fotografias de Francisco Ontañón, nas quais predominam cenas de rua, dialogam com o texto de Carandell, mas este não faz referências diretas a essas imagens. 0 fotolivro, além de se apresentar como um passeio pelos diversos territórios da capital espanhola, incluindo um verdadeiro mostruário dialetal e de tipos sociais, desenvolve também uma série de comentários irônicos

26 Do original: Lo primero que has de saber que en la corte hay siempre el más necio y el más sabio, más rico y más pobre, y los extremos de todas las cosas...

7 Do original: De esos dos millones y medio de habitantes que no sabemos quienes son, como piensan ni como viven, hay una representación completa en la chocolatería de Lavapiés, a las cinco de la mañana. 28 Do original: Madrid, al amanecer, es de Velázquez. De día, es de Goya. Las casas de los ricos, los jardines, los paseos, los edificios públicos y los bares elegantes son de Velázquez. El Rastro, los mercados, la Casa de Campo, los domingos, la Puerta del Sol, el Gran San Blas, el metro y las tascas son de Goya. sobre a sociedade madrilenha do período franquista, dirigidos em particular à parcela composta por "senhores antigos", "sinhozinhos andaluzes" e novos ricos empenhados em ascender socialmente. Por outro lado, a empatia com os tipos populares e desvalidos de Madri fica evidente na parte do livro intitulada "Goya":

Se em Velázquez a Espanha estava morta, em Goya parecia ter ressuscitado. Assim como Velázquez, Goya tomou nota do que estava ocorrendo. Uma nobreza corrompida na corte, enquanto na rua, o povo lhe quebrava o galho. Goya começou pintando a nobreza por obrigação, mas acabou gostando. Pintou-os com caras de palhaço, de degenerado e de torresmo. Goya pôs na moda a degeneração, assim como Velázquez havia posto na moda a languidez. Talvez por isso seja difícil ser elegante na Espanha sem ter um certo ar de cretinismo ${ }^{29}$ (CARANDELL, 1971, p. 81).

E, mais adiante, no mesmo capítulo, arremata:

Mas Goya está identificado com o povo e, mais concretamente, com o povo de Madri. No Rastro, na pradaria, na quermesse de San Isidro, na Puerta del Sol ainda se veem goyas viventes. Os domingos lhes pertencem. São seus os bairros humildes. E os mendigos e as prostitutas. E todos aqueles que não são nobres, nem burgueses, nem ricos do interior, nem sinhozinhos andaluzes, nem funcionários; os que não têm nada a defender e não fazem mais que se defender ${ }^{30}$ (CARANDELL, 1971, p. 83, tradução nossa).

Embora situado em pleno século XX, o texto de Carandell se conecta a toda uma tradição literária que remonta tanto a Benito Pérez Galdós ${ }^{31}$ como a já

29 Do original: Si en Velázquez España estaba muerta, en Goya parecía haber resucitado. Al igual que Velázquez, Goya tomó nota de lo que estaba ocurriendo. Una nobleza corrompida en la corte, mientras en la calle, el pueblo le sacaba a esa nobleza las castañas del fuego. Goya empezó pintando a la nobleza por obligación, pero luego le cogió gusto. Les pintó cara de payaso, de degenerado, de torresmo [sic], Goya puso de moda la degeneración, igual que Velázquez había puesto de moda la languidez. Tal vez por esta razón es difícil ser elegante en España sin tener un cierto aire de cretinismo.

30 Do original: Pero Goya está identificado con el pueblo, y muy concretamente con el pueblo de Madrid. En el Rastro, en la pradera, en la verbena de San Isidro, en la puerta del Sol se ven todavía goyas vivientes. Los domingos le pertenecen. Son suyos los barrios humildes. Y los mendigos y las prostitutas. Y todos aquellos que no son nobles, ni burgueses, ni ricos de pueblo, ni señoritos andaluces, ni funcionarios; los que no tienen nada que defender y no hacen otra cosa que defenderse.

${ }_{1}$ Pérez Galdós foi não só o principal representante da corrente realista na Espanha, tendo produzido uma obra extensa e relevante, como desempenhou um papel fundamental para a consolidação do romance em seu país. 
mencionada corrente costumbrista. Os dois trechos anteriormente citados poderiam ser vistos como uma referência indireta a Misericordia (1897) ${ }^{32}$, romance de Galdós em que também se destacam as duas caras de Madri, além das possíveis conexões com os artigos que o escritor escreveu para o jornal argentino La Prensa, entre 1883 e 1894, nos quais apresentava, para seus leitores de além-mar, as muitas facetas da capital espanhola. Essa suposta relação com a obra galdosiana é acentuada pelo tom crítico utilizado por Carandell em seu texto, no qual aponta, de forma indireta, para as desigualdades que o regime franquista, instalado no poder desde 1939, só fazia cultivar e aprofundar.

Já a relação entre texto e imagem, intensificada em publicações como Vivir en Madrid, também nos remete às obras clássicas do costumbrismo oitocentista, que combinavam crônicas e desenhos, como é o caso de Los españoles pintados por sí mismos ${ }^{33}$, cuja primeira edição é de 1842 . 0 gênero costumbrista, que estava diretamente relacionado ao movimento romântico europeu, teve repercussão também em países latino-americanos, em especial, no México. Nessas publicações, a descrição literária de costumes e de elementos considerados típicos ia acompanhada pela representação visual, dando origem, posteriormente, ao subgênero dos "tipos". Esse subgênero, que consistia em um relato sobre certo personagem com determinadas características - como as de ofício, formas de falar, de se vestir etc. -, acabava tendendo para a conformação de estereótipos. Embora o costumbrismo tenha tido uma inclinação maior para o conservadorismo político e social, alguns escritores, como Mariano José de Larra, aproveitaram esse tipo de escrita para apontar as mazelas sociais de seu tempo. Ao se remontar, em plena década de 1960, à tradição costumbrista oitocentista, possivelmente Luis Carandell se associava mais a essa tendência crítica de Larra.

Misericordia tem como protagonista a figura magnânima de uma mendiga, Benigna, que circula por diversos territórios de Madri, acompanhada por Almudena, um marroquino cego, miserável e fantasioso. 0 romance, que aponta a hipocrisia da sociedade espanhola da época, começa da seguinte forma: "Dos caras, como algunas personas, tiene la parroquia de San Sebastian... mejor será decir la iglesia... dos caras que seguramente son más graciosas que bonitas: con la una mira a los barrios bajos, enfilándolos por la calle de Cañizares; con la otra al señorío mercantil de la Plaza del Ángel" (PÉREZ GALDÓS, 1991, p. 61-62).

33 Los españoles pintados por sí mismos é uma obra publicada na Espanha, entre 1843 e 1844. Trata-se de uma coleção que contém noventa e oito relatos que descrevem personagens urbanos ("tipos"), sendo cada um deles acompanhado por sua respectiva ilustração. Dividida em dois tomos, a obra reuniu diversos escritores, incluindo os mais conhecidos da época: Ramón de Mesonero Romanos (conhecido como "El Curioso Parlante"), o Duque de Rivas, José Zorrilla e Estébanez Calderón, entre outros.
A estreita relação com o costumbrismo também pode ser observada nas Nuevas escenas matritenses, livro que reúne sete séries de fotografias de Enrique Palazuelo ${ }^{34}$ e relatos de Camilo José Cela, num total de 63 fotorrelatos. Originalmente, as sete séries foram publicadas em sete cadernos independentes, de maio de 1965 a outubro de 1966, na coleção Fotografias al minuto, da editora Alfaguara, portanto, um ano antes de Vivir en Madrid. Como observa Christoph Rodiek (2008, p. 125), o ponto de partida dos relatos de Cela são as fotografias realizadas por Palazuelo, entretanto, longe de fazer comentários referenciais sobre as imagens, o escritor as inclui em seu universo ficcional. Enquanto na tradição costumbrista do século XIX, a ilustração buscava ressaltar os aspectos mais evidentes do texto, nas Nuevas escenas matritenses, Cela utiliza as imagens como abertura para um "fora de campo" ficcional, dando nomes excêntricos aos personagens anônimos das fotos e empregando sua ironia desgarrada para criar cenas e diálogos que ampliam enormemente o campo semântico da imagem e que muitas vezes, longe de reforçar os elementos que a compõem, geram tensões entre o texto e a fotografia. De acordo com Rodiek (2008, p. 129, tradução nossa), “Cela le as fotos à sua personalíssima maneira e tende, progressivamente, a deformar os personagens" 35 .

Enquanto na primeira série dos forrelatos, o escritor mantém uma proximidade maior com as respectivas fotos de Palazuelo, nas demais as referências às imagens são cada vez mais distantes. Assim, na "cena" de abertura, intitulada "Nicasio Alcoba en la calle de las Huertas", vê-se a fotografia de um homem de costas, meio curvado, vestido com um paletó surrado, um jornal dobrado no bolso, olhando atentamente para os manequins da vitrine do salão de beleza Ramos. 0 relato de Cela acompanha os elementos da imagem, mas cria uma biografia fictícia para o personagem: "Nicasio Alcoba passa todas as manhãs pela rua das Huertas. Nicasio Alcoba, natural de Piedrabuena, província de Ciudad Real, está sobrando em Madri, mas não vai embora" ${ }^{36}$ (CELA, 1988, p. 12, tradução nossa). Outros dados são acrescentados para aumentar a verossimilhança e compor uma figura mais

34 Sabe-se que Enrique Palazuelo foi tenente da marinha e velejador, mas há poucos dados sobre ele. Na Fundación Camilo José Cela, se conservam cerca de 250 fotografias da época em que realizou seu trabalho fotográfico sobre Madri. Não foi possível encontrar os detentores de seus direitos autorais para reproduzir imagens suas neste trabalho.

35 Do original: Cela lee las fotos a su personalísima manera y tiende, progresivamente, a deformar a los personajes.

36 Do original: Nicasio Alcoba pasa todas las mañanas por la calle de las Huertas. Nicasio Alcoba, natural de Piedrabuena, provincia de Ciudad Real, está de más en Madrid, pero no se va. 
complexa: Nicasio Alcoba é peão, desempregado, serviu no exército republicano durante a guerra civil, o que lhe custou dois anos de campo de concentração, e agora está meio tísico. 0 personagem, por sua vez, também cria biografias fictícias dos manequins da vitrine, incluindo um que se parece ao próprio Camilo José Cela. Se a fotografia de Palazuelo nos apresenta o homem pobre que observa atentamente a vitrine luxuosa, remetendo às desigualdades da estratificada sociedade espanhola dos anos 1950/1960, o texto de Cela transforma a figura da foto em personagem de ficção e faz com que ele participe do jogo tornando-se criador de outros tantos personagens, inclusive, de um que poderia ser o próprio escritor.

O fotorrelato número 4, da quinta série, "Tres pies para un banco: Zamora, Ciriaco, Quincoces", é um dos exemplos em que a conexão entre texto e imagem não é imediata. A fotografia nos mostra uma cena de um bairro periférico de Madri. No primeiro plano da imagem, vemos três meninos de idades diferentes: enquanto o maior conserta uma bola improvisada, o do meio o observa e o menor, na outra ponta da foto, caminha em sua direção. Ao fundo, se veem dois típicos prédios feitos de carregação para abrigar operários pobres. Os protagonistas do relato de Cela não fazem parte da fotografia de Palazuelo, mas são o seu fora de campo. Após uma breve descrição dos edifícios erguidos poucos anos antes e da vida que os habita, inicia-se um diálogo entre dois personagens aos quais o leitor não foi apresentado. A conversa gira em torno de Juanita, uma viúva que é descrita por um dos interlocutores como uma "ruína de mulher", que tem mau hálito, joanetes, mau humor e é meio cega. Logo nos damos conta de que aquele que assim a apresenta é o senhor Perpetuo Polvoredo Fernández, pai de Roque, o pedreiro que despencou de um andaime. Perpetuo Polvoredo é, portanto, sogro de Juanita e avô de três meninos de nove, sete e seis anos, chamados, respectivamente, Perpetuo, Roque e Ciriaco. 0 avô, que não faz parte da imagem, estaria conversando com um vizinho, enquanto olha os três netos brincarem e os imagina, no futuro, como três grandes jogadores de futebol: Zamora, Ciriaco e Quincoces ${ }^{37}$. Mais adiante, o relato apresenta o destino dos três filhos de Roque, que vão morar no interior com o avô; e o de sua viúva, que após algumas tentativas para sobreviver, acaba morrendo como

37 Ricardo Zamora (1901-1978), “El Divino”, foi goleiro do Real Madri e, durante os anos vinte e trinta, foi considerado um dos melhores goleiros do mundo. Ciriaco Errasti Suinaga (1904-1984) e Jacinto Quincoces López (1905-1997) também do Real Madri, jogaram com ele na defesa. Os três jogadores foram também da seleção espanhola de futebol. indigente: "Como ninguém solicitou seus restos, Juanita acabou jogada na sala de dissecação. Os estudantes de medicina costumam fazer piadas, algumas engraçadas, sobre os mortos da vez" ${ }^{38}$ (CELA, 1988, p. 197, tradução nossa).

A estratégia utilizada por Cela nos joga para fora do marco da imagem, impedindo o enternecimento com a cena das crianças, que brincam com uma bola improvisada num terreno baldio, e dificultando que seus leitores estabeleçam qualquer empatia com os personagens suburbanos que descreve. Esse é o caminho oposto ao seguido por Ana María Matute e Jaime Buesa em Libro de juegos para los niños de los otros (1961), ${ }^{39}$ onde as fotografias de Buesa desencadeiam textos que denunciam, à maneira poética de Matute, a infância desvalida das grandes cidades espanholas do pós-guerra civil. Por sua vez, a fotografia de Palazuelo, que nos mostra os edifícios como sombras gigantes sobre os três meninos, poderia fazer parte do livro de Matute e Buesa. 0 que se percebe, portanto, é que Cela lê a contrapelo a imagem realizada por Palazuelo e a utiliza para aumentar o seu acervo de relatos impiedosos, embora aí não faltem referências à infância pobre e à tragédia que rondava as famílias de operários no período franquista.

Como observa Christoph Rodiek (2008, p. 139), os personagens desses relatos curtos que compõem as Nuevas escenas matritenses, acompanhadas da fotografia documental de Palazuelo, são, na maior parte das vezes, caricaturas cuja essência se relaciona à visão esperpêntica do mundo ${ }^{40}$, presente na obra de Cela desde os seus apuntes carpetovetónicos. ${ }^{41}$ Para muitos críticos, como

Do original: Como nadie reclamó sus restos, la Juanita acabó en cuartos en la sala de disección. Los Do original: Como nadie reclamó sus restos, la Juanita acabó en cuartos en la sala de dise
estudiantes de medicina suelen hacer chistes, algunos graciosos, sobre los muertos del turno.

estudiantes de medicina suelen hacer chistes, algunos gracios

39 Fotolivro da coleção Palabra e Imagem, da Editora Lumen.

40 O esperpento é um conceito criado por Ramón María del Valle-Inclán (1866-1936), dramaturgo, poeta e romancista espanhol, através do qual a realidade é deformada pela exacerbação de seus traços feios e grotescos. $41 \quad$ No Prólogo de El gallego y su cuadrilla (1955), o próprio Cela define aquilo que denomina de apuntes carpetovetónicos: "O apunte carpetovetónico poderia ser algo assim como um esboço agridoce, entre caricatura e água-forte, narrado, desenhado ou pintado, de um tipo ou de um pedaço de vida peculiares de um determinado mundo: o que os geógrafos chamam, quase poeticamente, a Espanha árida", (CELA, 1981, p. 8, tradução n ossa). A palavra carpetovetónico se refere a carpetanos e vetones, povos de origem celta que habitaram a Península Ibérica antes da chegada dos romanos. Sendo assim, a palavra indica aquilo que é característico da Espanha profunda. Durante a guerra civil, o termo foi bastante utilizado para fazer alusão à terra seca de Castela e ao que é rude, bruto e violento. Segundo o próprio Cela, o apunte (apontamento esboço) não é um artigo, uma vez que não se articula com nada, nem um conto, já que é carente de abstração e subjetividade. 0 autor explica, ainda, que seu apunte carpetovetónico, enquanto gênero literário, não éa nenhuma novidade, ligando-o à tradição literária espanhola desde as coplas medievais e, especialmente, à é nenhuma novidade, ligando-o à tradição literária espanhola desde as coplas medievais e, especialmente, passarolo sarnoso, acossado e ferozmente ibérico", (CELA, 1981, p. 9, tradução nossa). 
José María Castellet, esse tipo de recurso utilizado pelo escritor galego denota uma comicidade amarga e muitas vezes gratuita, o que é possível observar tanto em Izas, rabizas y colipoterras quanto em Nuevas escenas matritenses. Já a fotografia documental de Enrique Palazuelo se aproxima à praticada por Joan Colom, Jaime Buesa e toda uma nova geração de fotógrafos que, a partir dos anos 1950, passa a rechaçar a estética predominante do franquismo. Como explica Rodiek (2008, p. 126), na fotografia espanhola, até então, predominava o "neopictorialismo", cujos temas eram, dentre outros, a dignidade, a honra, a paz e a harmonia da vida rural. "Esses fotógrafos - afirma o crítico - pintavam, com um patetismo insuperável, procissões austeras, castelos sublimes, monges estatuários, aristocratas orgulhosos, etc." ${ }^{22}$ (2008, p. 126). 0 realismo documental surge, então, na contramão dessa tendência, evitando a retórica artificial dos pictorialistas e buscando captar o momento e, principalmente, aspectos da vida cotidiana. Nesse sentido, as grandes cidades, por sua quase infinita diversidade e seu incessante movimento, se tornam símbolo da própria modernidade e o modelo preferido da fotografia documental.

\section{Considerações finais}

Todas as obras mencionadas e analisadas neste trabalho nos levam, do ponto de vista temático, às representações do universo das grandes cidades, seja ao desejo utópico de transformá-las e construí-las como espaços emblemáticos da modernidade, seja à necessidade de reter elementos que constituem sua memória: cenas, tipos urbanos, lugares, falas, tradições etc. Os primeiros exemplos aqui referidos - Buenos Aires, Buenos Aires, Doorway to Brasilia e Brasília vive! - nos situam nessas cidades escritas e imaginadas como lugares atados a vivências passadas e as suas múltiplas referências ou a elementos que projetam o sonhado espaço futuro, onde já começam a se imiscuir suas primeiras distopias. Por outro lado, os fotolivros publicados na Espanha nos anos sessenta nos possibilitaram a reflexão em torno da cidade escrita e fotografada, assim como a observação do cultivo do neocostumbrismo -

42 Do original: Esos fotógrafos pintaban, con patetismo insuperable, procesiones austeras, castillos sublimes, monjes estatuarios, aristócratas orgullosos etc. como nos casos de Vivir en Madrid e das Nuevas escenas matritenses -, mas, principalmente, uma imersão nas relações entre literatura e fotografia.

A transformação dos modos de visão e de representação tradicionais introduzida pela fotografia-documento, conforme adverte André Rouillé, que se traduz nas imagens fragmentárias e não hierarquizadas dos fotolivros aqui apresentados, também altera de maneira significativa as relações entre texto e imagem. Enquanto os relatos do costumbrismo oitocentista descreviam tipos humanos de forma muitas vezes estereotipada e eram acompanhados por desenhos ilustrativos que ressaltavam seus aspectos mais emblemáticos, os fotolivros de Camilo José Cela, Joan Colom e Enrique Palazuelo apresentam uma relação complexa, e muitas vezes surpreendente, entre texto e imagem. Para compreender a peculiaridade desse acercamento foi preciso realizar um percurso que nos levou também a outras obras do próprio Cela e ao fotolivro Vivir en Madrid, de Luis Carandel e Francisco Ontañón, cujas referências são mais próximas à tradição literária espanhola do século XIX, em especial, ao costumbrismo crítico de Mariano José de Larra. Nas Escenas Matritenses foi possível observar as estratégias utilizadas pelo Camilo José Cela para criar biografias fictícias das figuras retratadas por Enrique Palazuelo, onde não faltam nomes e apelidos estrambóticos, diálogos carregados de termos populares e cotidianos, além de todo tipo de ironia e tiradas zombeteiras. Também foi possível perceber nos fotorrelatos os distanciamentos entre texto e imagem, conforme já apontara Christoph Rodiek. Cela não só joga com a credibilidade da fotografia-documento, como pratica uma leitura das imagens que afirma a potencialidade do entrecruzamento dos dois meios, antecipando um fenômeno contemporâneo que Natalia Brizuela (2014, p. 13), utilizando um termo de Mario Bellatín, denomina de "literatura nas fronteiras", ou seja, uma literatura situada numa zona porosa, propícia à contaminação de outras arte e à metamorfose. 


\section{Referências}

AGUILAR FERNÁNDEZ, Paloma. Políticas de la memoria y memorias de la política. Madrid: Alianza, 2008.

BRIZUELA, Natalia. Depois da fotografia: uma literatura fora de si. Trad. Carlos Nougué. Rio de Janeiro: Rocco, 2014.

CARANDELL, Luis; ONTAÑón, Francisco, Vivir en Madrid. 4. ed. Barcelona: Kairón, 1971.

CELA, Camilo José. El gallego y su cuadrilla. Barcelona: Destino, 1981.

CELA, Camilo José; COLOM, Joan. Izas, rabizas y colipoterras. Barcelona: Lumen, 1984.

CELA, Camilo José. Izas, rabizas y colipoterras: Drama con acompañamiento de cachondeo y dolor de corazón. Barcelona: Lumen, 1971.

CELA, Camilo José; MASPONS; UBIÑA. Toreo de salón: farsa con acompañamiento de clamor y murga. Barcelona: Lumen, 1963.

CELA, Camilo José; PALAZUELO, Enrique. Nuevas escenas matritenses. Barcelona: Círculo de Lectores, 1988.

CELA, Camilo José. Viaje a la Alcarria: las botas de siete leguas. $20^{0}$ ed. Madrid: Espasa-Calpe, 1989.

CORTÁZAR, Julio; FACIO, Sara; D’AMICO, Alicia. Buenos Aires Buenos Aires. Buenos Aires: Editorial Sudamericana, 1968.

CRARY, Jonathan. Técnicas do observador: visão e modernidade no século XIX. Trad. Verrah Chamma. Rio de Janeiro: Contraponto, 2015.

ESCOBAR ARONIS, José. Literatura de "lo que pasa entre nosotros". La modernidad del costumbrismo. Alicante: Biblioteca Virtual Cervantes, 2005

Disponível em: http://www.cervantesvirtual.com/obra-visor/literatura-de-lo-que-pasaentre-nosotros-la-modernidad-del-artculo-de-costumbrismo-0/html/0070efca-82b2-11dfacc7-002185ce6064_2.html. Acesso em: 15 fev. 2019.

FERNÁNDEZ, Horacio. Fotolivros latino-americanos. Trad. Gênese Andrade. São Paulo: Cosac Naify, 2011.
FONTCUBERTA, Joan. Izas, rabizas y colipoterras: un álbum furtiu. Catalan Review, Liverpool, v. XVIII, n. 1-2, 1998. Disponível em: https://www.raco.cat/index.php/CatalanReview/article/ view/310019. Acesso em: 17 fev. 2019.

FONTCUBERTA, Joan. O beijo de Judas: fotografia e verdade. Trad. Maria Alzira Brum Lemos, Barcelona: Ed. Gustavo Gili, 2010.

GALDÓS, Benito Pérez. Misericordia. Madrid: Cátedra, 1991.

MAGALHÃES, Aloísio; FELDMAN, Eugene. Doorway to Brasilia. Prólogo de John dos Passos. Philadelphia: Falcon Press, 1959

MATUTE, Ana María; BUESA, Jaime. Libro de juegos para los hijos de los otros. Barcelona: Lumen, 1961

SCHEIER, Peter; KONX, John. Brasília vive. Rio de Janeiro: Livraria Kosmos Editora, 1960.

RODIEK, Christoph. Del cuento al relato híbrido: en torno a la narrativa breve de Camilo José Cela Madrid; Frankfurt: Iberoamericana; Vervuert, 2008. https://doi.org/10.31819/9783964561664

ROUILLÉ, André. A fotografia: entre documento e arte contemporânea. Trad. Constância Egrejas. São Paulo: Ed. Senac, 2009.

SALAS C., María Esther. Genealogía de los mexicanos pintados por sí mismos. Historia Mexicana, Ciudad de México, v. XLVIII, n. 2, oct./dic., 1998.

SARLO, Beatriz. La ciudad vista: Mercancias y cultura urbana. Buenos Aires: Siglo Veintiuno Editores, 2010.

SCHØLLHAMMER, Karl Erik. Além do visível: o olhar da literatura. Rio de Janeiro: 7 Letras, 2016.

SOSNOWSKI, Saúl. El que vuelve: está en casa: Buenos Aires en Cortázar. In: Casa de las Américas, 2014. Disponível em: http://www.casadelasamericas.org/publicaciones/revistacasa/278/ notas.pdf. Acesso em 13 fev. 2019.

TUSQUETS, Esther. Prólogo: Casi cincuenta años después. In: VARGAS LLOSA; MISERACH, Xavier. Los cachorros. Madrid: La Fábrica, 2010. 